\title{
Higher Education in Italy: Spatial Accessibility, Participation and Drop-outs
}

\author{
Umut Türk \\ University of Verona, Italy \\ E-mail: umut.turk@univr.it
}

Received: November 11, $2017 \quad$ Accepted: November 30, 2017

doi:10.5296/ber.v8i1.12135

URL: https://doi.org/10.5296/ber.v8i1.12135

\begin{abstract}
Most previous research has focused on individual and family characteristics as predictors of high school leavers' behaviour towards higher education. However, far too little attention has been paid to the spatial dimension of the subject. This paper aims to narrow this gap by studying whether spatial accessibility of universities from parental residences influences the decisions of higher education participation and dropouts once enrolled to a university in Italy. First a modified version of Hansen gravity index measures the accessibility of HE institutions then a Probit model uses computed access scores across Italian provinces (NUTS3 level regions) to explore likelihood of university attendance and completion. The results show that spatial accessibility is influential when deciding to enrol a university and for successfully completing a degree.
\end{abstract}

Keywords: Higher education accessibility, Enrolment, Dropouts, Gravity index

\section{Introduction}

The determinants of higher education (HE) participation and the probability of completing a degree have been extensively analysed for different countries. The manner is of particular importance for Italy, since the country suffers from the lowest HE participation and graduation rates among OECD countries (OECD, 2011). Numerous papers have been produced to tackle this issue (see for instance: Checchi et. al, 1999; Di Pietro, 2004-2006; Triventi and Trivellato, 2009; Bratti et. all, 2008; Aina, 2013). In these papers and many others, the choice behaviour of students concerning the HE is generally investigated by the predictors of individual and family background characteristics, such as gender, age previous educational records as well as parental income and education (see for instance: Blanchfield, 1972; Smith and Naylor, 2001; Galindo-Rueda and Vignoles, 2005). So far, however, there has been a little discussion of the spatial accessibility of HE institutions in influencing university entry and dropouts and none for its implications in the Italian context (see Sá and 
Rietveld, 2006 for Duch students; Gibbons and Vignoles, 2012 for British students).

The assumption concerning spatial accessibility is that the larger is the distance from HE opportunities, the smaller the HE accessibility is. Especially for students with poor family backgrounds proximity to a university may be crucial when deciding to enrol at a university. The underlying idea is that students from more isolated locations must face larger constraints to reach universities, with costs growing with spatial distance between parental residences and HE opportunities. Distance to university influences the likelihood of participation and the HE outcomes of students (see for example McHugh and Morgan, 1984; Tinto, 1973; Ordovensky, 1995; Gibbons and Vignoles, 2009; Suhonen, 2014; Turk, 2017). This is because, the costs of commuting or migrating may deter access or impose a barrier when enrolling at a university. In the case of Italy, majority of students enrol at a university closest to parental residences and commuting is traditionally common among students living in relatively smaller cities. This is partially owing to the costs of living independently of parents and there are also physiological reasons related to willingness to live away from parents. The latter is especially relevant as Italy is characterised by strong family ties (Alesina and Giuliano, 2010). Therefore, in Italy spatial access to university is a particularly important factor, which can potentially increase enrolment rates and the likelihood of successfully completing a degree.

This paper studies a spatial dimension of student behaviour towards HE and addresses following questions: whether the accessibility of $\mathrm{HE}$ institutions from parental residences affects students' decision to participate in HE and to what extent it is influential for students who drop out of universities. Based on a data survey conducted by the National Institute for Statistics (ISTAT), the paper investigates the likelihood of university participation and dropouts given the level of spatial HE-access from parental residences. Spatial access is measured with a Hansen-like gravity index and resulting distribution of access scores among Italian provinces (NUTS3 level regions) is used in a Probit model predicting the likelihood of college attendance and completion for those who attended to a university in the year 2007 . Findings indicate that spatial access to HE institutions increases the likelihood of both university participation and successfully completing a bachelor's degree.

The reminder of the paper is organised as follows: section 2 describes the data and section 3 presents findings and finally section 4 concludes. In section 2 the modified version of Hansen gravity index is presented.

\section{Data and Methods}

Data used in the analysis are drawn from a survey carried out by the National Institute for Statistics (ISTAT) in 2011 on individuals who successfully graduated from high schools in 2007. The same data has been used several times to investigate the same phenomenon. However, spatial accessibility is incorporated in analysis as a first time by this paper.

Data includes information on the characteristics of family backgrounds and the previous educational information of students. The information of the students who enrolled a university and those who dropped out after enrolment is readily available in the dataset. To avoid potential biases associated with the time of enrolment, only the population who 
enrolled at a university right after high school is considered and for the investigation of drop out behaviour, the observations who are still students are not taken into consideration.

The key information used in this paper includes residences before enrolling at a university (parental residence) and the name of the university enrolled (if any). The two information are used to compute Euclidean distance between the exact addresses of the largest university campuses and parental residences, the computed distance is used both for measuring spatial access to HE and also directly included when modelling dropouts.

Moreover, the empirical analysis exploits the following set of individual and family background variables: individual characteristics include gender, age and the type of high school completed. Survey does not contain information on family income, but it reports both parents' profession and educational level when the student was 14. All types of parental professions are included in the model as dummies and parental education variable as the highest level of educational attainment by either parent: at least a university degree (see Table $1)$.

Table 1. Variables used in Analysis

\begin{tabular}{|l|l|}
\hline Variables & Description \\
\hline Residence & Province of residence before enrolment \\
\hline Destination University & Enrolled University 63 state and 14 private universities \\
\hline Distance & Euclidean distance between city centroids and University addresses, \\
& measured in QGIS based on coordinates \\
\hline Female & $1=$ Female, 0=Male \\
& 3,314 male and 4,729 female total students \\
\hline Age & Age in 2007 (19-30 years old) \\
\hline High school Type & -Vocational Schools \\
\hline & -Technical Schools \\
\hline & -Liceo (General) Schools \\
\hline & -Pedagogical Schools \\
\hline Parental Education & -Artistic Schools \\
\hline Father's Occupation Type & Whether the highest educational level recorded by any of the \\
& parents is at least university degree. \\
\hline & - Executive employees \\
\hline & - High/medium qualifications \\
\hline & -Officials \\
\hline & - Managers \\
\hline & - Self Employed \\
\hline
\end{tabular}

\subsection{Measuring Access}

Spatial accessibility of universities from parental residences is measured by a Hansen-like gravity index as follows:

$$
A_{i}=\sum_{j} \frac{C_{j}}{d_{i j}^{-\widehat{\beta} P_{P o p}}}
$$

where $A_{i}$ is the accessibility of universities at location $i, C_{-} j$ is the number of available places offered by university $j$ in a given year, $d_{i j}$ is the distance between $i-j, \hat{\beta}$ is 
distance decay factor, which is empirically derived by a spatial interaction model ${ }^{1}$ finally $\mathrm{Pop}_{j}$ is the total population of 19 to 21 year-olds in $j$.

Distance function $d_{i j}^{-\widehat{\beta}}$ takes several forms such as the exponential form, exponential square root, the log of distance or a relevant combination of these (De Vries et al, 2009). In this paper, distance is modelled in a power specification. Indeed, the power-decay function has been found to be more suitable for long distance interactions owing to the log-cost perception (Fotheringham and Webber, 1980; Reggiani et al, 2011). Moreover, the geo-referenced information as to where the student lives is at province scale (NUTS3 level regions) but university locations are exact (the largest campuses). Therefore, even within a province zero distance does not occur, which in return provides the index with a higher precision accounting for the mobility within a province: commuting students. The assumption is that all students depart from city centroids when reaching to university. Moreover, accessibility is determined by the distribution of universities and that of youth. Because most of the university programmes are offered in an open access fashion in Italy, implying that the only constraint is the number of places offered by universities.

Figure 1 shows the distribution of 19 to 21 -year-old population per province. The map renders a higher concentration of the youth in the far south and north of country. This means that for these geographical areas, the supply of HE must be relatively higher to provide equal spatial access. This condition is tested later in this section by the spatial accessibility index.

Using access measures in the place of distance has several advantages. Since there is no university choice revealed, distance to university cannot be used for the analysis of enrolment behaviour. In this respect, HE-access from parental residences is a useful and necessary predictor that allows to study the spatial dimension of HE participation decisions. Moreover, including spatial accessibility as a continuous variable rather than a dummy (a dummy simply representing commutable universities see for instance Frette, 2001) implicitly accounts for the preferences of students: some students may have a university in commutable distance but prefer to study in another university which is far from parental residence but relatively easy to reach for weekly visits to home. This is because spatial distance from institutions along with other financial constraints may affect the choice of institution better matching the student's ability and preferences. Therefore, having a larger set of universities available from home (whether in commuting distance or not) may increase students' tendency to pursue an academic carrier. Therefore, a correct measure of spatial accessibility should include

${ }^{1}$ Distance decay is derived by spatial interaction models as follows: $T_{i j}=O_{i} D_{j} d_{i j}^{-\beta}$ where $T_{i j}$ is a count of students who have parental residences at $i$ and study at $j . O_{i}$ is a set of municipality dummies, $D_{j}$ is the total number of students who enrolled university $j$ where the higher the $D_{j}$ is the more attractive the university, $d_{i j}$ is the distance between parental residence and university, and $\beta$ is distance decay factor. The data is extracted from a data survey (Inserimento professionale dei laureati, 2011) including 14,000 male and 17,400 female graduates in 2007 . 


\section{Macrothink}

Business and Economic Research

ISSN 2162-4860

2018, Vol. 8, No. 1

continuous values indicating the degree of potential benefit from all HE institutions. Another advantage of using spatial accessibly has to do with the decay function used in Hansen-like gravity index. The distance decay factor is empirically derived by exploiting the previous information on interaction between students and universities and shows distance elasticities i.e. how far students are willing to commute or migrate given the spatial distance and implicitly their preferences. Universities that receive higher flows of students are considered as attractive and distance to these becomes less important. Hence for these universities a lower decay value yields. Moreover, distance to university indicates both physical and psychological costs of relocation. In particular, the role of distance may strike through costs of living: students who migrate to attend a university education face greater costs than those who stay at home. It is also indicative for the ability to live alone, far from parents and such conditions may pose time constraints related to house works (cleaning, cooking etc.). Regarding this last point, the likelihood of dropping out may increase with exposure to low HE access. Indeed, we can test the relevance of computed HE accessibility scores in the analysis of dropouts. Since the information of university choice is known in this scenario, both distance and accessibility can be used. If the likelihood of completing a degree is negatively related to spatial distance to university then a positive relationship between completion and HE access must be observed. The results concerning this point are reported in the findings section.

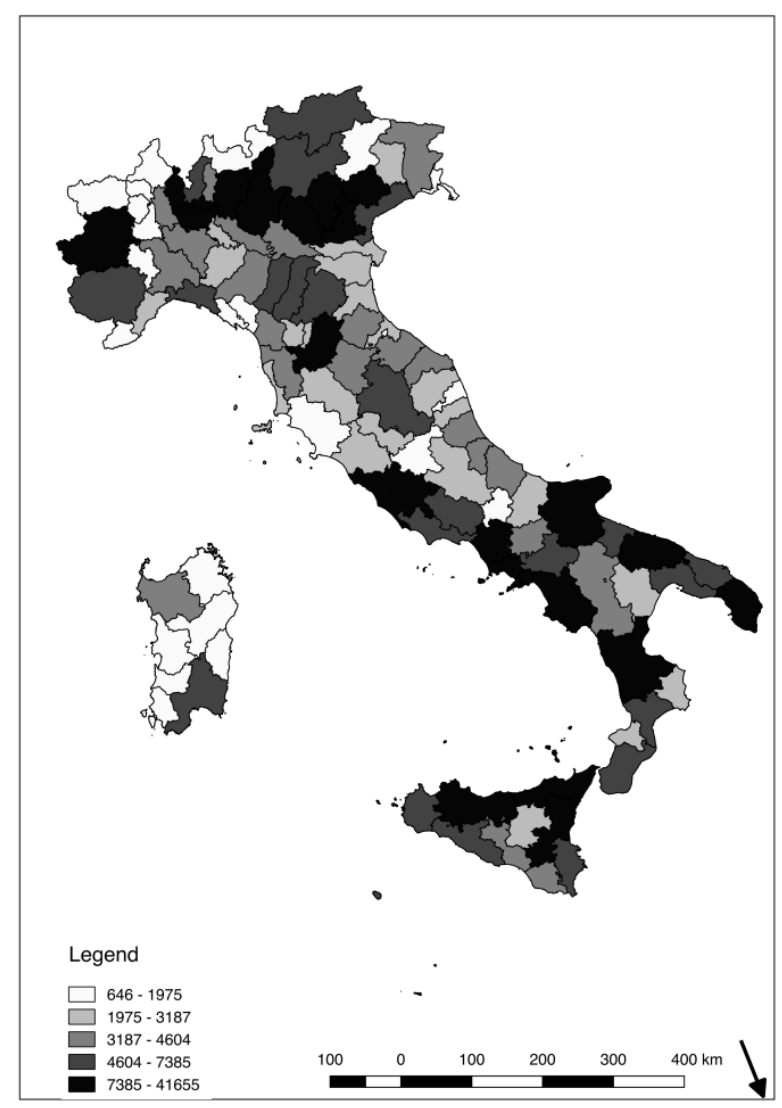

Figure 1. Concentration of 19to 21-year olds in 2007

Figure 2 illustrates the distribution of access per province. The measured scores show 


\section{Macrothink}

potential access in terms of the total number of places offered to students in 2007. Higher scores indicate better access to 77 total number of universities located in 101 different provinces. Spatial access is particularly low in the south and in Sicily and Sardinia, two islands of the country. A higher access yields in the centre and north of the country. This result confirms the traditional North-centre-south (including islands) division of opportunities in the country. Although there is a higher population of youngsters in Milan, Rome and Naples, in these cities spatial access is higher than others. This is because these cities contain more than one university, hence higher number of places available to students.

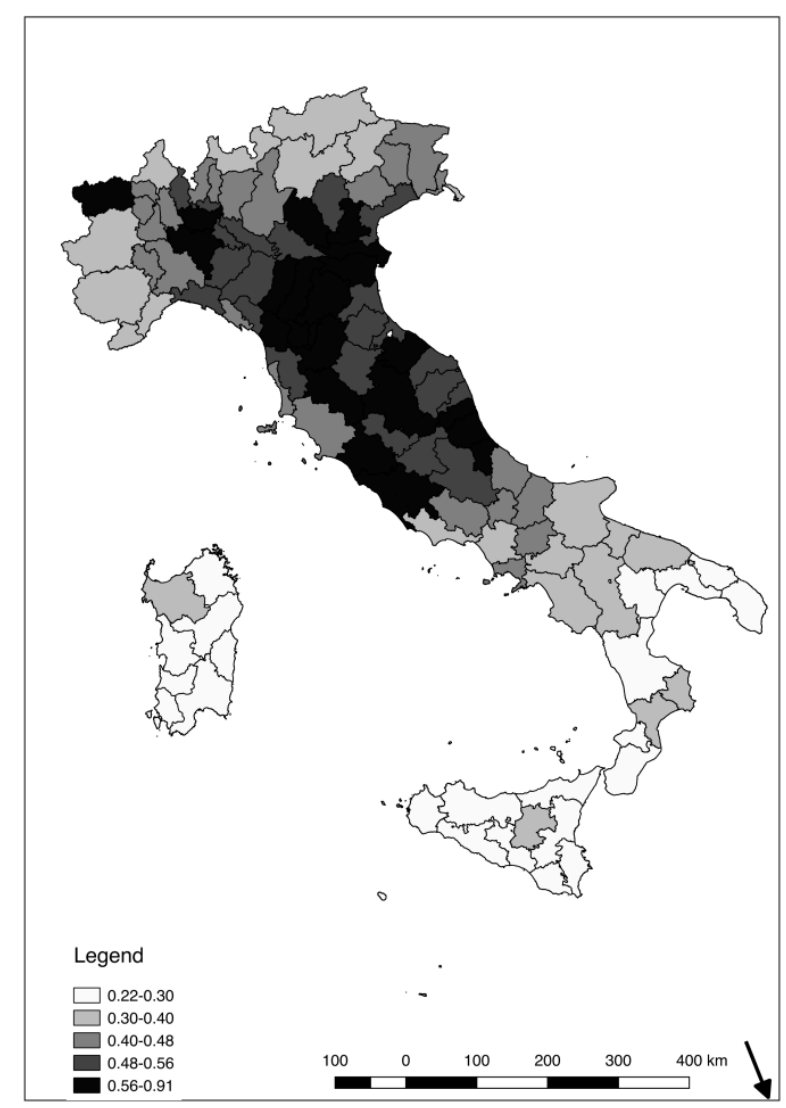

Figure 2. Spatial Accessibility of universities in 2007

\subsection{The Model}

The probability of HE participation is modelled as a function of spatial accessibility of universities and a set of individual controls. Similarly, the probability of completing a degree is modelled as a function of both spatial accessibility of universities and distance separately and a set of individual controls. The models take the following forms:

$$
P_{i}(\text { Enrol })=f\left(A_{i j}, F_{i}, I_{i}\right)
$$

and

$$
P_{i}(\text { Complete })=f\left(A_{i j}, F_{i}, I_{i}\right)
$$

where $P_{i}($ Enrol $)$ and $P_{i}$ (Complete) are the probabilities of individual $i$ to attend, and 
complete a degree respectively, $A_{i j}$ is accessibility of universities from a location $j$ where individual $i$ has parental residence (i.e. residence before enrolling to a university), $F_{i}$ and $I_{i}$ are a set of family and individual characteristics, respectively.

Empirically the following model is estimated for both cases:

$$
\begin{gathered}
y_{1 i}^{*}=\alpha+\beta_{1} x_{1}+\varepsilon_{1 i}, \varepsilon_{1 i} \sim N(0,1) \text { and } y_{2 i}^{*}=\alpha+\beta_{2} x_{2}+\varepsilon_{2 i}, \varepsilon_{2 i} \sim N(0,1) \\
y_{1 i}\left\{\begin{array}{c}
0 \text { if do not enrol a university }\left(y_{1 i}^{*}<0\right) \\
1 \text { if enrols a university }\left(y_{1 i}^{*} \geq 0\right)
\end{array}\right.
\end{gathered}
$$

similarly, $\quad y_{2 i}\left\{\begin{array}{l}0 \text { if drops out of } \operatorname{HE}\left(y_{2 i}^{*}<0\right) \\ 1 \text { if completes succesffuly }\left(y_{2 i}^{*} \geq 0\right)\end{array}\right.$

where linear changes in the Probit produce nonlinear changes in the probability of enrolment in $y_{1 i}$ and successfully completing a degree in $y_{2 i}$.

\section{Findings}

The results of the Probit model for the likelihood of enrolment and completion are shown on Table 1 and Table 2, respectively. Table 1 indicates that a higher access to HE increases the likelihood of university enrolment. Similarly, Table 2 shows that the effect of spatial accessibility to $\mathrm{HE}$ is statistically significant and positively (negatively) associated with completing a degree (dropouts).

The coefficients of spatial access variables show that geographical accessibility plays a significant role in determining the enrolment choices of students to HE and the impact is especially strong for the likelihood of completing a degree. As far as the model of enrolment is concerned, this is an important result because it suggests that the HE participation in part is related to the spatial proximity of HE opportunities from home. Therefore, looking at the accessibility map in Fig.2, the residential areas with lighter grey have lower likelihood of HE education participation and as for the macro regions, the students from southern regions have relatively less access to $\mathrm{HE}$ and hence less likely to enrol a university compared to those from central and northern regions. This result, suggesting the statistically significant impact of spatial access, confirms the findings of Sa et al (2004) for Dutch students and further extends our understanding on the role of HE accessibility with the analysis of dropouts.

For the analysis of drop out behaviour both accessibility and distance are used in separate regressions. The first and second columns of Table 2 include spatial access. In both outputs, it emerges as an important factor (significant at 0.01 level) increasing the likelihood of obtaining a university degree. This is an interesting result since it suggests that the spatial access level in 2007, hence when the decision to enrol was taken, remains significant for successfully completing a university. The interpretation is twofold. The families who live in the provinces with higher spatial access to universities might be those who sort in these areas for their children's education. Thus, the children of these families receive strong support from their parents for obtaining a degree. Although the model controls for family characteristics, this sorting behaviour might be one of the driving forces of the findings. Anyway, the 


\section{Ml Macrothink}

Business and Economic Research

ISSN 2162-4860

2018, Vol. 8, No. 1

residential decisions taken by parents are exogenous to students, thus exogenous to the model. The second interpretation is that the students whose parental residences are in the areas with low spatial access to HE must commute longer distances or migrate to other destinations, this has its drawbacks as explained above (physical and physiological costs). This is also evident from the third and fourth columns of Table 2, where spatial distance to university substitutes spatial accessibility of universities. As the spatial distance between parental residence and universities increases, students become less likely to complete a degree.

Table 2. Estimates of the probability of university enrolment

\begin{tabular}{|c|c|c|}
\hline & (1) & (2) \\
\hline Variables & Marginal Effects on Enrolment & Marginal Effects on Enrolment \\
\hline \multirow[t]{2}{*}{ Accessibility } & $0.227 * *$ & $0.268 * *$ \\
\hline & $(0.107)$ & $(0.109)$ \\
\hline \multirow[t]{2}{*}{ Age } & $-0.254 * * *$ & $-0.264 * * *$ \\
\hline & $(0.021)$ & $(0.0220$ \\
\hline \multirow[t]{2}{*}{ Female } & $0.097 * * *$ & $0.0965 * * *$ \\
\hline & $(0.034)$ & $(0.0344)$ \\
\hline High School Type: & (ref:Art Schools) & \\
\hline \multirow[t]{2}{*}{ Vocational Schools } & $-0.146^{* * *}$ & $-0.158 * * *$ \\
\hline & $(0.0550)$ & $(0.0561)$ \\
\hline \multirow[t]{2}{*}{ Technical Schools } & $0.309 * * *$ & $0.305 * * *$ \\
\hline & $(0.053)$ & $(0.054)$ \\
\hline \multirow[t]{2}{*}{ General Schools (Licei) } & $0.965 * * *$ & $0.971 * * *$ \\
\hline & $(0.060)$ & $(0.061)$ \\
\hline \multirow[t]{2}{*}{ Pedagogical Schools } & $0.771 * * *$ & $0.775 * * *$ \\
\hline & $(0.062)$ & $(0.063)$ \\
\hline \multirow[t]{2}{*}{$\begin{array}{l}\text { Father's Occupation } \\
\text { Executive employees }\end{array}$} & (ref: Blue collar): & $0.292 * * *$ \\
\hline & & $(0.053)$ \\
\hline \multirow[t]{2}{*}{ High or medium qualifications } & & $0.322 * * *$ \\
\hline & & $(0.052)$ \\
\hline \multirow[t]{2}{*}{ Officials } & & $0.527 * * *$ \\
\hline & & $(0.081)$ \\
\hline \multirow[t]{2}{*}{ Managers } & & $0.388 * * *$ \\
\hline & & $(0.099)$ \\
\hline \multirow[t]{2}{*}{ Self Employed } & & $0.237 * * *$ \\
\hline & & $(0.041)$ \\
\hline \multirow[t]{2}{*}{ Parent's Education } & $0.249 * * *$ & \\
\hline & $(0.025)$ & \\
\hline \multirow[t]{2}{*}{ Constant } & $0.606 * * *$ & $0.564 * * *$ \\
\hline & $(0.087)$ & $(0.090)$ \\
\hline Observations & 8,043 & 7,792 \\
\hline
\end{tabular}

Robust standard errors in parentheses $* * * \mathrm{p}<0.01, * * \mathrm{p}<0.05, * \mathrm{p}<0.1$

As far as the controls are concerned, in contrast with the previous findings (see for instance Checchi, 2000) there is a statistically significant difference between genders for enrolment. Female students are more likely to enrol at a university after high school. The likely explanation is that this paper uses a more recent survey and the higher participation rates by 


\section{Macrothink}

Business and Economic Research

ISSN 2162-4860

2018, Vol. 8, No. 1

females might be a recent development. Moreover, this result is in line with previous findings that education is the primary area where women have made substantial gains (DiPrete and Buchmann, 2006). Interestingly, however, gender does not seem to play a role in completing a degree. Although the coefficients of female dummy are positive in Table 2, they are not statistically significant. After the decision to participate in HE is taken place, gender must be becoming irrelevant. Moreover, the coefficients of the age variable indicate that older students (those who delay high school graduation) are less likely to enrol at and complete a university.

While costs also discourage enrolments, evidence suggests that high school background is a prevailing factor in deciding whether to attend a university. A similar conclusion can be drawn from Tables 1 and 2. The empirical results illustrate that high school type is strongly related to students' likelihood of transition from high school to university. Table 1 indicates that graduating from a vocational school decreases the likelihood of university participation. The interpretation is that since vocational schools prepare students directly for job market, the students graduating from these schools tend to choose working rather than going on with higher education. The coefficients of vocational school (not significant but negative) on Table 2 indicate that they are also less likely obtain a university degree. This is probably because they are less prepared for university education (Di Pietro, 2004). As far as family background is concerned, two proxies are used alternately since education level and occupation type might be endogenous. As expected, the first columns of Table 1 and 2 show that the highest degree attained by either parent increases the likelihood of both enrolment and completion. As regards to enrolment model, the alternative specification is shown on the second column where all occupation types are statistically significant with positive coefficient signs. The "Officials" category shows a higher impact than others. This category includes teachers (of schools from primary school to high school). Hence, the interpretation is that this group is more likely to invest in education given their close relations with it. The lowest coefficient yields for "self employed" fathers. The likely explanation is that the students of these families might take over the jobs of their fathers and cease their studies after high school. 
Table 3. Estimates of the probability of university completion

\begin{tabular}{|c|c|c|c|c|}
\hline & (1) & (2) & (3) & (4) \\
\hline VARIABLES & $\begin{array}{c}\text { Marginal Effects on } \\
\text { Enrolment }\end{array}$ & $\begin{array}{c}\text { Marginal Effects on } \\
\text { Enrolment }\end{array}$ & $\begin{array}{c}\text { Marginal Effects on } \\
\text { Enrolment }\end{array}$ & $\begin{array}{c}\text { Marginal Effects on } \\
\text { Enrolment }\end{array}$ \\
\hline \multirow[t]{2}{*}{ Access } & $0.698 * * *$ & $0.711^{* * *}$ & & \\
\hline & $(0.250)$ & $(0.253)$ & & \\
\hline \multirow[t]{2}{*}{ Age } & $-0.353 * * *$ & $-0.343 * * *$ & $-0.367 * * *$ & $-0.361 * * *$ \\
\hline & $(0.0734)$ & $(0.0751)$ & $(0.0754)$ & $(0.0773)$ \\
\hline \multirow[t]{2}{*}{ Female } & 0.0430 & 0.0361 & 0.0191 & 0.00977 \\
\hline & $(0.0814)$ & $(0.0825)$ & $(0.0831)$ & $(0.0844)$ \\
\hline \multirow[t]{2}{*}{ Vocational } & -0.0888 & -0.0907 & -0.0821 & -0.0761 \\
\hline & $(0.175)$ & $(0.177)$ & $(0.178)$ & $(0.180)$ \\
\hline \multirow[t]{2}{*}{ Technical } & $0.327 * *$ & $0.307 * *$ & $0.293 *$ & $0.271 *$ \\
\hline & $(0.152)$ & $(0.154)$ & $(0.154)$ & $(0.157)$ \\
\hline \multirow[t]{2}{*}{ General Schools } & $0.841 * * *$ & $0.835 * * *$ & $0.832 * * *$ & $0.826 * * *$ \\
\hline & $(0.150)$ & $(0.153)$ & $(0.151)$ & $(0.155)$ \\
\hline \multirow[t]{2}{*}{ Pedagogical Sch. } & $0.350 * *$ & $0.340^{* *}$ & $0.364 * *$ & $0.358 * *$ \\
\hline & $(0.161)$ & $(0.164)$ & $(0.161)$ & $(0.165)$ \\
\hline $\begin{array}{l}\text { Father's Occupation: } \\
\text { Executive } \\
\text { employees }\end{array}$ & (ref: Blue collar) & $\begin{array}{c}0.202 \\
(0.128) \\
\end{array}$ & & $\begin{array}{c}0.183 \\
(0.131) \\
\end{array}$ \\
\hline $\begin{array}{l}\text { High/medium } \\
\text { qualifications }\end{array}$ & & $\begin{array}{c}0.192 \\
(0.125) \\
\end{array}$ & & $\begin{array}{c}0.209 \\
(0.128)\end{array}$ \\
\hline \multirow[t]{2}{*}{ Officials } & & $0.298^{*}$ & & $0.333^{* *}$ \\
\hline & & $(0.155)$ & & $(0.163)$ \\
\hline \multirow[t]{2}{*}{ Managers } & & 0.133 & & 0.148 \\
\hline & & $(0.200)$ & & $(0.207)$ \\
\hline \multirow[t]{2}{*}{ Self Employed } & & $0.213 * *$ & & $0.203 *$ \\
\hline & & $(0.104)$ & & $(0.105)$ \\
\hline \multirow[t]{2}{*}{ Parent's Edu } & $0.202 * *$ & & $0.236 * * *$ & \\
\hline & $(0.0909)$ & & $(0.0916)$ & \\
\hline \multirow[t]{2}{*}{$\log ($ distance $)$} & & & $-0.144 * * *$ & $-0.142 * * *$ \\
\hline & & & $(0.0445)$ & $(0.0459)$ \\
\hline \multirow[t]{2}{*}{ Constant } & -0.314 & -0.321 & 0.394 & 0.421 \\
\hline & $(0.255)$ & $(0.255)$ & $(0.261)$ & $(0.266)$ \\
\hline Observations & 1,135 & 1,100 & 1,093 & 1,058 \\
\hline
\end{tabular}

Robust standard errors in parentheses $* * * \mathrm{p}<0.01, * * \mathrm{p}<0.05, * \mathrm{p}<0.1$

\section{Conclusions}

An equal access to $\mathrm{HE}$ is a goal that can produce positive outcomes both for students in question and for the society in general. This paper uses a survey conducted by the National Institute for Statistics (ISTAT) among Italian high school graduates for investigating the role of spatial accessibility of HE in university enrolment and drop-outs. The subject is of importance for the Italian context since it is characterized by the lowest graduation rates among all OECD countries. Even although the impact of individual and family characteristics have been extensively studied, this is the first paper measuring and including spatial accessibility of HE in such analysis for Italy.

The main conclusion drawn from the empirical findings is that spatial accessibility affects 
both decisions to participate in HE and the likelihood of completion a degree. In other words, spatial accessibility of universities exerts a positive impact on decisions to continue with university education after high school, and the students whose parental residences are in cities with high spatial access to HE institutions show higher likelihood of obtaining a degree. Moreover, the set of variables show that high school type and family's socio-economic status are important determinants of students' behaviour towards higher education.

Considering spatial accessibility to explain student behaviour after high school allows for new policy designs. Policy makers can identify the areas with low spatial access to HE and impose policies to decrease geographical barriers to reach universities. Such policies can take the form of increased supply by introducing new universities in the system or by increasing the capacity of existing universities. In particular to Italy, overall findings of this paper show that the spatial accessibility of universities must be increased especially in the southern parts of the country. Moreover, the controls concerning high school type suggest that it may be valuable for university attendance if the students of vocational schools are encouraged for further education.

The findings of this paper strongly recommend the use of spatial accessibility measure as a predictor of students' behaviour after high school graduation. However, it remains to be further clarified whether these findings could be compared with other countries. Future work will involve the application of proposed method to data from other contexts.

\section{References}

Aina, C. (2013). Parental background and university dropout in Italy. Higher Education, 65(4), 437-456. https://doi.org/10.1007/s10734-012-9554-z

Alesina, A., \& Giuliano, P. (2010). The power of the family. Journal of Economic growth, 15(2), 93-125. https://doi.org/10.1007/s10887-010-9052-z

Belloc, F., Maruotti, A., \& Petrella, L. (2010). University drop-out: an Italian experience. Higher Education, 60(2), 127-138.https://doi.org/10.1007/s10734-009-9290-1

Blanchfield, W. C. (1972). College dropout identification: An economic analysis. The Journal of Human Resources, 7(4), 540-544. https://doi.org/10.2307/144756

Bratti, M., Checchi, D., \& De Blasio, G. (2008). Does the expansion of higher education increase the equality of educational opportunities? Evidence from Italy. Labour, 22(s1), 53-88. https://doi.org/10.1111/j.1467-9914.2008.00411.x

Checchi, D. (2000). University education in Italy. International Journal of Manpower, 21(3/4), 177-205. https://doi.org/10.1108/01437720010335969

Checchi, D., Ichino, A., \& Rustichini, A. (1999). More equal but less mobile?: Education financing and intergenerational mobility in Italy and in the US. Journal of public economics, 74(3), 351-393. https://doi.org/10.1016/S0047-2727(99)00040-7

De Vries, J. J., Nijkamp, P., Rietveld, P. (2009) Exponential or power distance-decay for commuting? an alternative specification. Environment and Planning A, 41(2), 461-480. 
https://doi.org/10.1068/a39369

DiPrete, T. A., \& Buchmann, C. (2006). Gender-specific trends in the value of education and the emerging gender gap in college completion. Demography, 43(1), 1-24.

https://doi.org/10.1353/dem.2006.0003

Di Pietro, G. (2004). The determinants of university dropout in Italy: a bivariate probability model with sample selection. Applied Economics Letters, 11(3), 187-191.

https://doi.org/10.1080/1350485042000203832

Di Pietro, G. (2006). Regional labour market conditions and university dropout rates: Evidence from Italy. Regional Studies, 40(6), 617-630.

https://doi.org/10.1080/00343400600868770

Fotheringham, A. S., \& Webber, M. J. (1980). Spatial structure and the parameters of spatial inter- action models. Geographical Analysis, 12(1), 33-46.

https://doi.org/10.1111/j.1538-4632.1980.tb00016.x

Frenette, M. (2003). Access to college and university: Does distance matter. ottawa. Statistics Canada, Catalogue, (11F0019MIE2003201).

Galindo-Rueda, F., \& Vignoles, A. (2005). The declining relative importance of ability in predicting educational attainment. Journal of Human Resources, 40(2), 335-353. https://doi.org/10.3368/jhr.XL.2.335

Gibbons, S., \& Vignoles, A. (2012). Geography, choice and participation in higher education in England. Regional science and urban economics, 42(1), 98-113.

https://doi.org/10.1016/j.regsciurbeco.2011.07.004

McArthur, D. P., Kleppe, G., Thorsen, I., \& Ubøe, J. (2011). The spatial transferability of parameters in a gravity model of commuting flows. Journal of Transport Geography, 19(4), 596-605. https://doi.org/10.1016/j.jtrangeo.2010.06.014

OECD, (2011) Education at a glance 2011: OECD indicators. OECD Publishing Paris

Ordovensky, J. F. (1995). Effects of institutional attributes on enrollment choice: Implications for postsecondary vocational education. Economics of Education Review, 14(4), 335-350. https://doi.org/10.1016/0272-7757(95)00013-A

Reggiani, A., Bucci, P., \& Russo, G. (2011). Accessibility and network structures in the german commuting. Networks and Spatial Economics, 11(4), 621-641.

https://doi.org/10.1007/s11067-010-9149-0

Sá, C., Florax, R. J., \& Rietveld, P. (2006). Does accessibility to higher education matter? Choice behaviour of high school graduates in the Netherlands. Spatial Economic Analysis, l(2), 155-174. https://doi.org/10.1080/17421770601009791

Smith, J. P., \& Naylor, R. A. (2001). Dropping out of university: a statistical analysis of the probability of withdrawal for UK university students. Journal of the Royal Statistical Society: Series A (Statistics in Society), 164(2), 389-405. https://doi.org/10.1111/1467-985X.00209 


\section{Macrothink}

Business and Economic Research

ISSN 2162-4860 2018, Vol. 8, No. 1

Suhonen T. (2014). Field-of-study choice in higher education: Does distance matter? Spatial Economic Analysis, 9(4), 355-375. https://doi.org/10.1080/17421772.2014.961533

Tinto, V. (1973). College proximity and rates of college attendance. American Educational Research Journal, 10(4), 277-293. https://doi.org/10.3102/00028312010004277

Triventi, M., \& Trivellato, P. (2009). Participation, performance and inequality in Italian higher education in the 20th century. Higher Education, 57(6), 681-702.

https://doi.org/10.1007/s10734-008-9170-0

Turk, U. Socio-Economic Determinants of Student Mobility and Inequality of Access to Higher Education in Italy. https://doi.org/10.13140/RG.2.2.18803.73763

\section{Copyright Disclaimer}

Copyright for this article is retained by the author(s), with first publication rights granted to the journal.

This is an open-access article distributed under the terms and conditions of the Creative Commons Attribution license (http://creativecommons.org/licenses/by/3.0/). 